\title{
Erratum to: Diffusing Software Product and Process Innovations
}

\author{
Mark A. Ardis ${ }^{1}$ and Barbara L. Marcolin ${ }^{2}$ \\ 1 Rose-Hulman Institute of Technology, USA \\ 2 University of Calgary, Canada
}

Erratum to:

M.A. Ardis and B.L. Marcolin (Eds.)

Diffusing Software Product and Process

Innovations

DOI: $10.1007 / 978-0-387-35404-0$

The book was inadvertently published with an incorrect name of the copyright holder. The name of the copyright holder for this book is: (c) IFIP International Federation for Information Processing. The book has been updated with the changes. 